\title{
EFFECTS OF CLIMATE CHANGE ON FUTURE EXTREME RAINFALL INDICES OVER THAILAND
}

\section{MAIJANDEE S. \\ KREASUWUN J. KOMONJINDA S. PROMNOPAS W.}

Received: $17 / 09 / 13$

Accepted: 04/03/14

Available online: 19/03/2014

\author{
Department of Physics \\ Faculty of Science, Chiang Mai University, Chiang Ma \\ Thailand, 50200
}

*to whom all correspondence should be addressed: e-mail: tongjjj@hotmail.com

\section{ABSTRACT}

Extreme rainfall indices were calculated based on daily rainfall data derived from the outputs of MM5RCM simulations. Projected changes of these indices in the future (2020s) under the IPCC Special Report on Emissions Scenarios (SRES) A1B compared to the reference period (1990s) were analyzed. Before calculating the indices, the raw outputs from the MM5-RCM were adjusted in order to reduce biases as part of the bias-correction process. The validation demonstrates that the average and cycle of annual rainfall in the reference period are reproduced reasonably in the bias-corrected MM5-RCM results. The projected changes of the rainfall indices suggest that in the future most areas of northern, western, and northeastern Thailand will become wetter in the wet season and drier in the dry season. Central and eastern Thailand will become drier in the wet season while in the dry season rainfall will become more intense, and rainy days will become more scattered with a higher number of heavy rainfall days. In the south, the length of the wet spell will be decreased in the Southern Andaman Sea area and increased in East-Southern Region. The dry spell will likely be shorter throughout the southern region for all seasons.

Keywords: extreme rainfall, projected climate change, MM5-RCM, wet-dry spell

\section{Introduction}

Climate change resulting from the increasing concentration of $\mathrm{CO} 2$ and other greenhouse gas emissions has become evident. (Groisman et al., 1999; Houghton et al., 2001) There is increasing observational evidence indicating that the frequency and intensity of extreme precipitation events are sensitive to global climate change. (Karl et al., 1995; Zhai et al., 1999; Mccarthy et al., 2001) Increasing extreme precipitation has led to more frequent flood and drought disasters over many areas. (Houghton et al., 2001; Kothavala, 1997; Manabe et al., 1981) Potential changes in intensity and frequency of extreme precipitation due to climate change may result in serious adverse impacts on human life. Therefore, the analysis of extreme precipitation events in the present and future climate is of utmost importance (Oikonomou et al., 2008).

The Intergovernmental Panel on Climate Change (IPCC) had developed the Special Report on Emission Scenarios (SRES), which have been widely used in the analysis of climate change and its possible impacts. SRES presented four narrative storylines, labeled A1, A2, B1, and B2, describing the relationships between the forces driving greenhouse gases and aerosol emissions and their evolution (Solomon, 2007). Global climate models (GCMs) are well-established tools for studying climate change projections under various greenhouse gases emission scenarios on a global scale. Some research results, 
using GCM suggested that global warming may lead to a more intense hydrological cycle with an associated increase in the frequency and magnitude of heavy precipitation (Fowler and Hennessy, 1995). The most important disadvantage of the GCMs is that their application for studying regional climatic processes is limited due to their coarse spatial resolution which is in the range of a hundred kilometers. GCMs do not capture the effects of local and regional processes. Direct use of GCM outputs may therefore not be suitable for impact assessment on a regional scale. There is an essential need to improve the GCM outputs into a reliable data set that have higher spatial resolution. There are many approaches to improving the resolution of GCMs. The two main approaches are dynamical and statistical downscaling. Dynamical downscaling uses high-resolution regional climate models (RCMs) to represent global or regional sub-domains and uses either observed or lower-resolution GCM data as their boundary conditions. Statistical downscaling methods use cross-scale relationships that have been derived from observed data and apply these to climate model data (Solomon, 2007). However, simulation outputs are not always in a good accordance with observations. There may be some biases associated with the models. Sometimes, heavy rainfall and number of heavy rain days (as well as their magnitude) are not well reproduced by RCMs. Bias correction is therefore necessary in order to improve the input data for climate change impact assessments. The bias-corrected data is useful in the studies of impacts of climate change to extreme events and can be used as an input to other climate impact studies such as water resource, agriculture and environments.

The climate of Thailand is also experiencing a gradual warming as indicated by significant changes of temperature and rainfall extreme trends from observed records (Limjirakan and Limsakul, 2012; Limsakul et al., 2010; Chidthaisong, 2010). The objective of this study is to investigate the impact of climate changes on rainfall intensity, the frequency of heavy rainfall, and the duration of extreme dry and wet spells in Thailand for the future period 2020-2029 relative to the reference period 1990-1999 under the IPCC A1B emission scenarios. The simulated daily rainfall data of the MM5 RCM forced with CCSM3 were used to calculate the climate indices. The bias correction approach is employed in this study to reduce the MM5-RCM biases. Relative changes of extreme rainfall indices were calculated from the bias-corrected data (Post-MM5-RCM).

\section{Materials and methods}

\subsection{Data}

In this study the analysis of projected change of extreme indices was carried out using the simulated data from 50 stations shown in Figure 1 . These simulated rainfall data were provided by the Atmospheric Physics Research Unit, Faculty of Science, Chiang Mai University. The simulations are based on the principle of dynamical downscaling. In these simulations, the fifth-generation Pennsylvania State University NCAR Mesoscale Model (MM5) was forced by the National Center for Atmospheric Research (NCAR) Community Climate Model Version 3 (CCSM3) according to the IPCC SRES A1B scenario with the resolution of $15 \mathrm{~km}$ and the 3 -hourly temporal resolution. The physics options used include the BettsMiller cumulus scheme, the medium Range forecast planetary boundary layer (PBL), the mixed-phase (Reiner 2) Microphysics (explicit moisture) schemes, and the RRTM radiation scheme. The data at each station were taken from the value of the nearest grid point of the MM5-RCM simulations. Two time periods, namely 1990-1999 and 2020-2029, have been selected to represent the future and reference periods, respectively. Raw outputs from MM5-RCM were adjusted and validated by comparing with the observed data in 1980-1999 and 1990-1999 periods. The observational data were provided by the Thailand Meteorological Department. The spatial distribution of climate data is interpolated by the Kriging Method. All rainfall indices were calculated from the adjusted MM5-RCM (Post-MM5-RCM) outputs for both periods. The changes in the extreme rainfall indices in Thailand for the period 20202029 relative to 1990-1999 (future minus reference) were analyzed to investigate the impact of future climate changes on the rainfall intensity, the frequency of heavy rainfall, and the duration of extreme dry and wet spells in Thailand. 


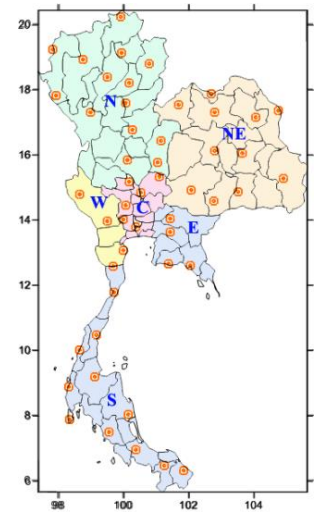

Figure 1. Location of the stations used in this study

\subsection{Rainfall bias-correction}

The bias correction approach is employed in this study to reduce the model biases. The bias correction algorithms were developed based on the comparison of observed data and the model output for the same time period. For rainfall correction, the direct method (DM, sometimes referred to as delta method) was applied. (Lehner et al., 2006; Lenderink et al., 2007; Wetterhall et al., 2012)The direct method scales the simulated rainfall by multiplying it with the ratio of observed and RCM-simulated rainfall. Let $\mathrm{P}_{\mathrm{MM} 5}, \mathrm{P}_{\text {post-MM5 }}, \overline{\mathrm{P}}_{\text {obs }}$, and $\overline{\mathrm{P}_{\mathrm{MM} 5}}$ denote the raw MM5-RCM, adjusted or bias-corrected MM5-RCM, mean observed, and mean raw MM5-RCM rainfall, respectively. The equation that is used to adjust the $P_{M M 5}$ to the $P_{\text {post-MM5 }}$ is

$\mathrm{P}_{\text {post-MM5 }}=\mathrm{P}_{\mathrm{MM} 5} \times \frac{\overline{\mathrm{P}_{\mathrm{obs}}}}{\overline{\mathrm{P}_{\mathrm{MM} 5}}}$

Note that the parameters $\overline{\mathrm{P}_{\mathrm{obs}}} / \overline{\mathrm{P}_{\mathrm{MM}}}$ were calculated for each station in each month using data from the 1980-1999 period.

\subsection{Extreme rainfall indices}

Extreme rainfall events are defined by the aid of five precipitation indices which are recommended by the joint Working Group on Climate Change Detection of the World Meteorological Organization Commission for Climatology (WMO-CCL) and the research program on Climate Variability and Predictability (CLIVAR). A dry day is a day with less than $1 \mathrm{~mm}$ of rainfall, while a wet day is the day with a rainfall amount greater than or equal to $1 \mathrm{~mm}$. The following indices as listed in Table 1 are employed.

Table 1. The extreme rainfall indices used in this study

\begin{tabular}{cll}
\hline ID & \multicolumn{1}{c}{ Name } & \multicolumn{1}{c}{ Description } \\
\hline SDII & $\begin{array}{l}\text { Simple daily precipitation } \\
\text { intensity index }\end{array}$ & $\begin{array}{l}\text { The ratio of annual or seasonal total rainfall to the } \\
\text { number of days during the year or season when there is } \\
\text { rainfall greater than or equal to } 1 \mathrm{~mm} .\end{array}$ \\
\hline Rnn* & $\begin{array}{l}\text { The number of heavy rainfall } \\
\text { days }\end{array}$ & $\begin{array}{l}\text { An indicator of the heavy rainfall frequency. It is the } \\
\text { annual or seasonal total number of the days with rainfall } \\
\text { amount greater than the nn value. }\end{array}$ \\
\hline CWD & $\begin{array}{l}\text { Consecutive wet days or the } \\
\text { maximum wet spell }\end{array}$ & $\begin{array}{l}\text { The annual or seasonal longest period of consecutive } \\
\text { days with at least 1mm of rainfall. }\end{array}$ \\
\hline CDD & $\begin{array}{l}\text { Consecutive dry days or the } \\
\text { maximum dry spell }\end{array}$ & $\begin{array}{l}\text { The annual or seasonal longest period of consecutive } \\
\text { days with no or less than 1 mm of rainfall }\end{array}$ \\
\hline Rx5day & Maximum 5-day rainfall amount & The monthly maximum consecutive 5-day rainfall amount \\
\hline
\end{tabular}

Note that the $n n^{*}$ in the Rnn index denoted the $95^{\text {th }}$ percentile of rainfall amount in the base period, which was calculated for each station (Suwanmanee, 2012). Thailand has a wide variety of climate and 
rainfall in different areas. Using a fixed $n n$ value for measuring heavy rainfall days is not appropriate; for example, heavy rain in the North may not be considered heavy in the South. Therefore, using an independent threshold for each station is more proper.

The calculations of rainfall indices were performed by using RClimDex software, developed and maintained on behalf of the Expert Team on Climate Change Detection and Indices(ETCCDI) by the Climate Research Branch of the Meteorological Service of Canada. The indices are calculated for the present period (1990-1999) and for the future period (2020-2029) on annual and seasonal bases from the Post-MM5-RCM data.

The extreme rainfall indices were calculated based on annual and seasonal bases, namely the wet (May October) and dry (November - April) seasons.

\section{Results and discussion}

\subsection{Rainfall Validation}

All extreme rainfall indices are calculated from the simulated daily rainfall. In order to evaluate the rainfall data, the average annual total rainfall from observed and Post-MM5-RCM precipitation during the reference period (1990-1999) were compared as shown in Figure 2.

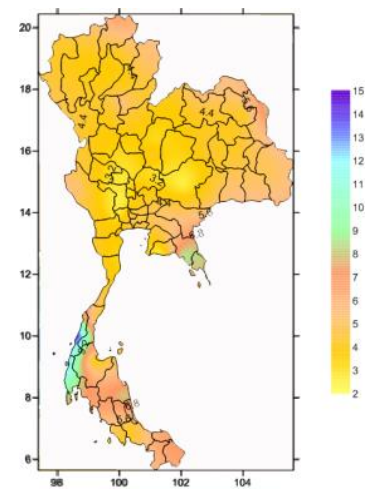

(a)

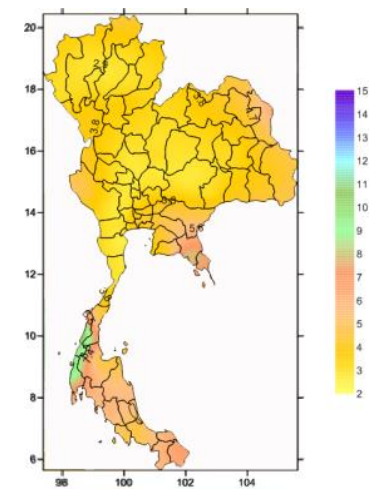

(b)

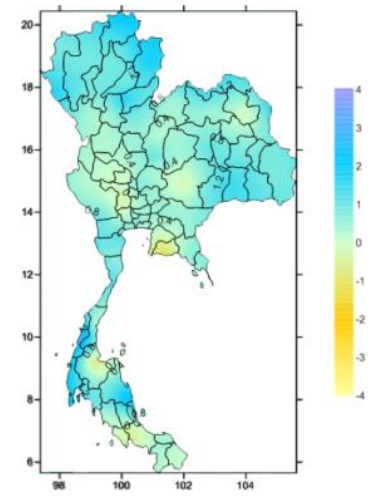

(c)

Figure 2. The annual average rainfall (unit: $\mathrm{mm} \mathrm{day}^{-1}$ ) from Post-MM5-RCM simulation (a) and observation (b) along with the differences between both datasets on annual basis (c)

The results show that the Post-MM5-RCM rainfall corresponds well with the observed data. The average total rainfall amount from Post-MM5-RCM is, in general, slightly overestimated in comparison with the observed data; the biases range from -1.25-3.29 with an average of $0.78 \mathrm{~mm}$ day $^{-1}$ (Figure 2c). Most biases are noticed in the stations in the upper north of the country. Several observed large rainfall areas in 1990-1999 are well captured in the Post-MM5-RCM results, including those over Trad and Chanthaburi provinces, and also the stations along the southwestern region.

Figure 3 shows the annual cycle of rainfall in the 1990-1999 reference period of some selected stations. The climatologically mean annual cycles of the observations are plotted in red while the Post-MM5-RCM values are plotted in blue. The results show that the annual cycles in all stations previously mentioned are reasonably reproduced by the Post-MM5-RCM with correlation coefficients greater than 0.94 . The Post-MM5-RCM rainfalls present higher amounts than the observation but follow the trend of the annual cycle. The Post-MM5-RCM rainfalls show an agreement with the observed ones with the maximum in August at the Phitsanulok and PrachinBuri stations, and the maximum in September was at the Bangkok Metropolis station. The pronounced summer rainfall and dual peak of observed rainfall can be seen in the Post-MM5-RCM results of the Bangkok Metropolis and Phitsanulok stations (Figure 3a 
and 3d) but is missing in the PrachinBuri station (Figure 3b). The Post-MM5-RCM rainfall amount is close to the observed amount during September-December for all stations.

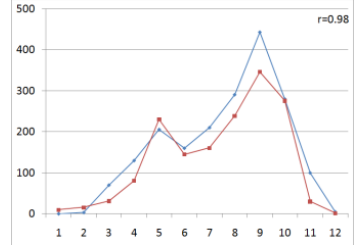

(a)

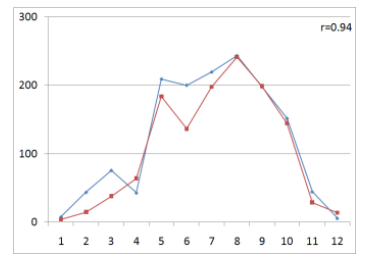

(d)

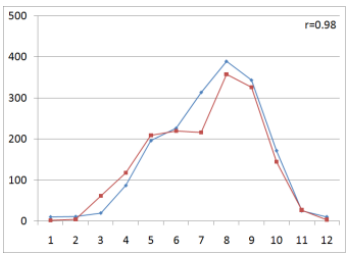

(b)

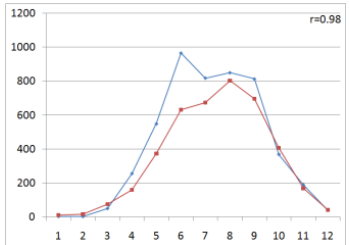

(e)

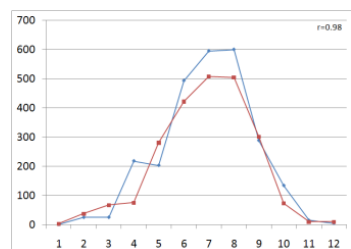

(c)

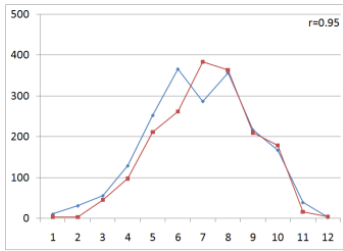

(f)

Figure 3.The mean annual cycle of rainfall in the 1990-1999 reference period ( (a) Bangkok Metropolis

(b) PrachinBuri (c) NakhonPhanom (d) Phitsanulok (e) Ranong, and (f) Thong PhaPhum stations); $r$ denotes the correlation coefficient between Post-MM5-RCM and observed rainfall on a monthly basis

\subsection{Projected changes of extreme rainfall indices}

\subsubsection{SDII (Simple daily precipitation intensity index)}

The SDII index is an indicator of rainfall intensity on a wet day. The projected changes of SDII in the 2020-2029 period relative to the reference period are shown in Figure 4.

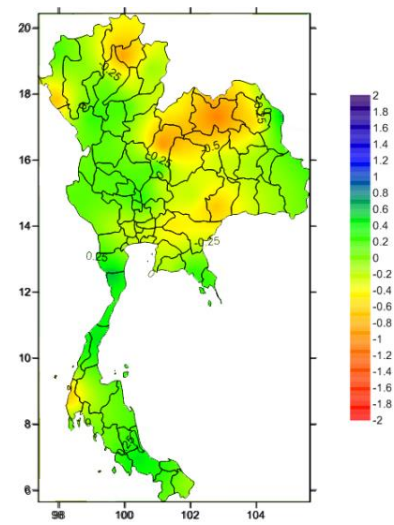

(a:annual)

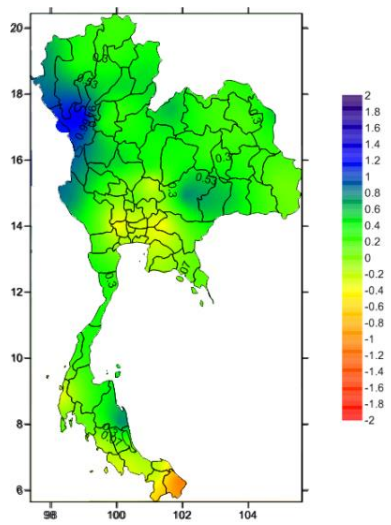

(b: wet season)

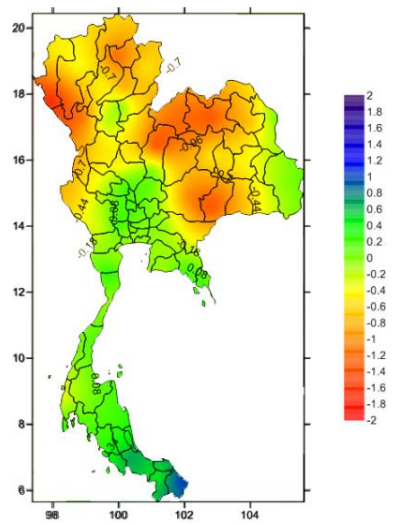

(c: dry season)

Figure 4. The projected changes of SDII in the future relative to the reference period (unit: $\mathrm{mm} \mathrm{day}^{-1}$ )

During the wet season, increases in rainfall intensity (mostly within 0.04-1.34 $\mathrm{mm} \mathrm{day}^{-1}$ ) are expected in most stations over northern, northeastern, and western Thailand where the maximum increase is up to $1.34 \mathrm{~mm} \mathrm{day}^{-1}$. Reductions in rainfall intensity within $0.02-1.06 \mathrm{~mm}$ day $^{-1}$ are possibly evident in the central, east, and lower-south of the country. During the dry season, the opposite change is predicted. The stations in upper Thailand (except the central and eastern parts) tend to have less rainfall intensity within the change of $-0.02--1.65 \mathrm{~mm}$ day $^{-1}$ while more rainfall intensity $\left(0.02-0.99 \mathrm{~mm} \mathrm{day}^{-1}\right.$ more than the reference period amount) can be expected in most stations over the remaining areas of the country. On an annual basis, decreases of rainfall intensity (about $-0.02--1.07 \mathrm{~mm} \mathrm{day}^{-1}$ ) are likely to be found in 
the stations over most areas of northeastern, central, and some areas in eastern, southern, and northern Thailand. Most stations over southern and western Thailand are expected to have $0.01-0.62$ $\mathrm{mm}$ day $^{-1}$ of more intense rainfall on a wet day in the future.

\subsubsection{Rnn (Number of Heavy Rainfall Days)}

The Rnn index indicates the frequency of heavy rainfall days. The projected changes of Rnn in the 20202029 period relative to the reference period are shown in Figure 5.

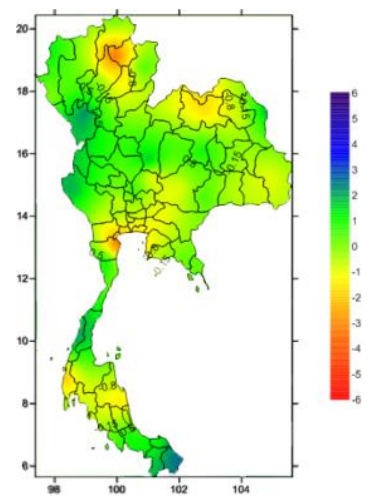

(a:annual)

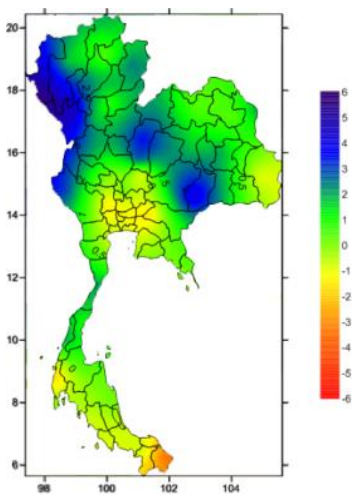

(b: wet season)

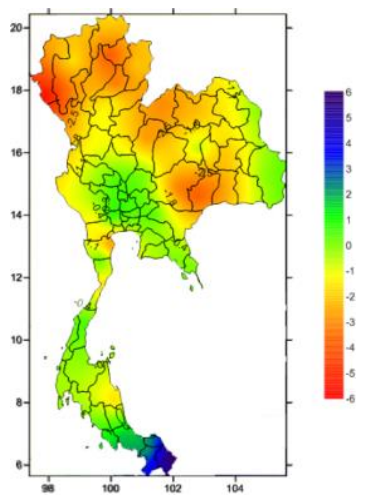

(c: dry season)

Figure 5. The projected changes of Rnn in the future relative to the reference period (unit: days)

The changes of Rnn in all seasons are in the same way as those of the SDII. In the wet season, more frequent heavy rainfall within $0.20-4.60$ days is possibly evident in most stations over the northern, western, northeastern, and upper-southern regions; the maximum increase in the number of heavy rainfall days is likely to be found over Mae Hong Son Province located in the northwest of the country where an increasing rate of 5.7 days is expected. In this season, the heavy rainfall days will become less frequent within $-0.30--3.40$ days in all stations over the central, some stations over the east, and westsouthern areas of Thailand. During the dry season, the number of heavy rainfall days may decrease in the future in all stations except some located over the central, east, and southern areas where increases of about 0.10-6.00 days are expected. The maximum decrease is found with the rate of -4.66 days over Mae Hong Son and Phayao Provinces. Significant decreases are predicted at most stations over the north and some stations over the northeast and south. On an annual basis, the results show that heavy rainfall will possibly become more frequent $(0.10-2.6$ days $)$ at some stations over the lower north, northeast, west, and south, and less frequent ( 0.10 - 3.50 days $)$ at the stations in the remaining areas as shown in Figure 5a.

\subsubsection{Rx5day (Maximum 5-day rainfall amount)}

The Rx5day index is defined as the monthly maximum consecutive 5-day rainfall amount. The projected changes of Rx5day in the period of 2020-2029 relative to the reference period are shown in Figure 6 .

As shown in Figure 6, the Rx5day will possibly change in the range of $-29.01-29.02 \mathrm{~mm}$ and -29.1 $28.00 \mathrm{~mm}$ during the wet and dry seasons. During the wet season, the maximum 5-day rainfall amount will likely decrease within $-0.22--29.1 \mathrm{~mm}$ in all stations over the central and some stations over the east and lower south of the country. The maximum significant increase $(29.02 \mathrm{~mm})$ and decrease $(-29.01$ $\mathrm{mm}$ ) are expected in Mae Hong Son and Narathiwat provinces that located in the northwest and the south, respectively. During the dry season, increases of the maximum 5-day rainfall amount within 0.87-28.00 are predicted in most stations over the south and some stations over the east. Maximum 5day rainfall amounts are expected less in most stations in upper Thailand. 


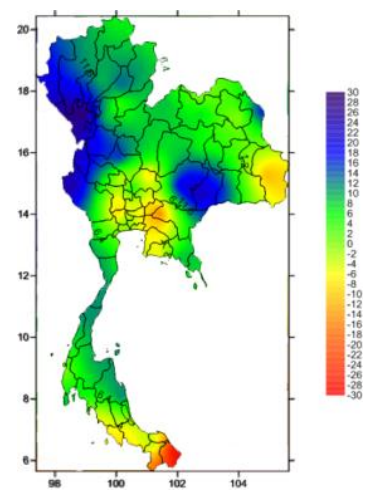

(a: wet season)

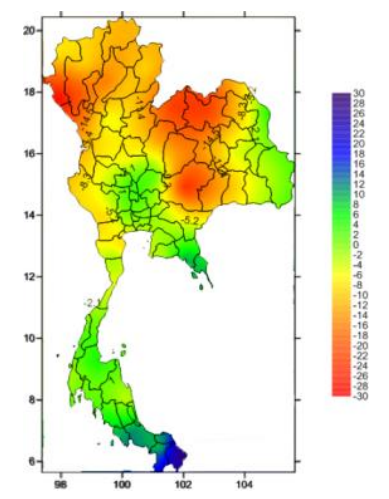

(b: dry season)

Figure 6. The projected changes of Rx5day in the future relative to the reference period (unit: $\mathrm{mm}$ )

\subsubsection{CWD (Consecutive wet days)}

The CWD index is an indicator of the maximum wet spell. The projected changes of CWD in the period of 2020-2029 relative to the reference period are shown in Figure 7.

The results of the CWD index during the wet season demonstrate that the future wet spell may be longer (within 0.22-4.01 days) in most stations over northern and northeastern Thailand and some stations over the southern part. A highlighted increase may be seen in the northwest of the country where the magnitude of the increase reaches 4.01 days. The shorter wet spell is also predicted in the remaining areas. During the dry season, CWD change is small compared with wet season. There is no pronounced change except in the stations over lower-southern Thailand, where increases in the wet spell are expected with the maximum increase reaching 4.00 days. In the stations over the remaining areas of country, the wet spell change ranges from -1.77 to 2.00 days. The slight decrease in wet spell can be seen at the stations over upper-northern, central, and eastern Thailand. A weak increase is apparent in northeastern and southern Thailand along with the lower region of northern Thailand.

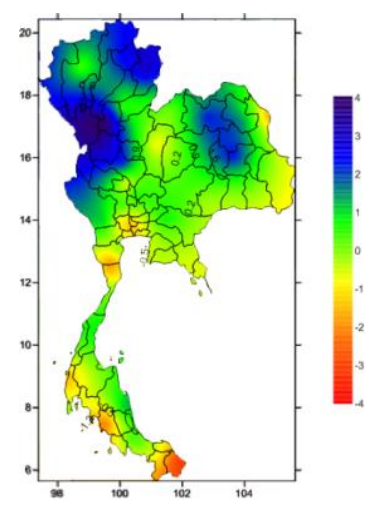

(a: wet season)

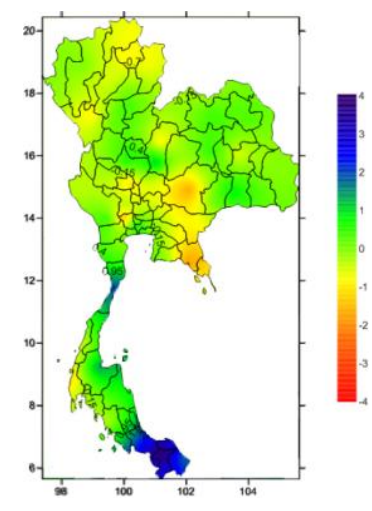

(b: dry season)

Figure 7. The projected changes of CWD in the future relative to the reference period (unit: days)

\subsubsection{CDD (Consecutive dry days)}

The CDD index is an indicator of the maximum dry spell. The projected changes of CDD in the period of 2020-2029 relative to the reference period are shown in Figure 8. 


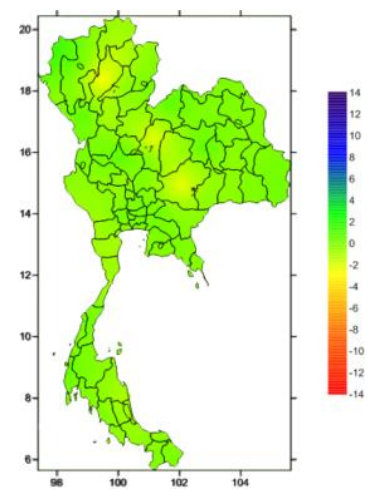

(a: wet season)

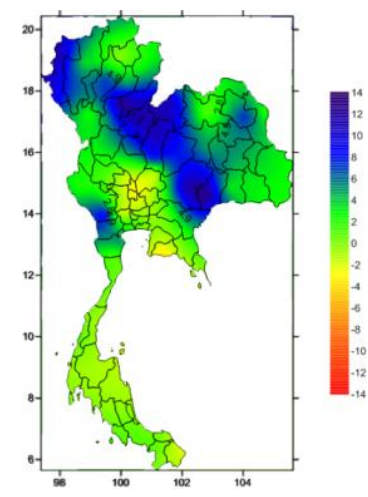

(b: dry season)

Figure 8. The projected changes of CDD in the future relative to the reference period (unit: days)

The number of CDD in the wet season is small compared with that in dry season; hence, the change of dry spell is limited. The considerable decreases in dry spell are probably noticed at the stations in the east of the north of the country and along the mountain range area in northeastern Thailand where the decrease is up to 2.8 days while in the remaining area the changes of dry spell are expected to be lower ranging from -1.4 to 1.6 days. Extremely dry spells are expected to be longer during the dry season in the future in most stations over northern, northeastern, and western Thailand. Large increases in magnitude are predicted at the stations mainly around Phetchabun and Sankamphaeng mountain ranges ranging from 7.2-13.9 days. Decreases of dry spell in the dry season can be expected in central, eastern, and southern Thailand at a range of 0.38-3.8 days.

\subsection{Discussions}

Validation of the average annual total rainfall archived from Post-MM5-RCM output against that from the station data for the 1990-1999 reference period demonstrates that the totals of annual rainfall are reproduced reasonably by Post-MM5-RCM. There is no significant difference in the distribution between the observed data and the bias-corrected simulations. Several large rainfall areas observed in 1990-1999 are well represented. Overall, rainfall was slightly overestimated. The comparison between the simulated and observed annual cycle of rainfall in the reference period shows an agreement in all stations. Most bias comes from the overestimation of rainfall.

The changes of the SDII, Rnn, and Rx5day indices are similar. This finding is consistent to some studies in other regions (e.g. Mizuta et al., 2005; Nastos, 2013) who found that increases of extreme rainfall indices are seen in most of the same regions. The changes of SDII and Rnn on an annual basis appear small while analyzing them on a seasonal basis renders these changes more obvious.

The increases of SDII, Rnn, Rx5day, CWD, and slight decrease of CDD in the stations over most areas of northern, western, and northeastern Thailand in the wet season indicate more intense and heavy frequent rainfall with a longer wet spell during the wet season when the country is influenced by tropical cyclone activity. These trends may be due to an increase of tropical cyclone genesis. A recent study indicated that global warming leads to a very significant increase in genesis of tropical cyclones in the South China Sea (Stowasser et al., 2007). During the dry season, it is the opposite; decreases of SDII, $\mathrm{Rnn}, \mathrm{Rx} 5 \mathrm{day}$, and CWD are predicted indicating less intense and heavy frequent rainfall with a shorter wet spell. From this, it can be concluded that in the future these areas will likely become wetter during the wet season and drier in dry season. This pattern of change in these areas is consistent with the change of mean rainfall from other studies in which an increase of rainfall during the rainy season and decrease in the dry season are predicted (Chotamonsak et. al., 2010; Chidthaisong, 2010). When considered in conjunction with the annual changes in the stations over lower-northern and western part of Thailand, increases in mean annual SDII and Rnn (Suwanmanee, 2012) indicate that these areas may 
be vulnerable to flooding in the future, in particular, the areas that have experienced flooding in the past. Likewise decreases in mean annual SDII and Rnn suggest that the northeast and upper-north will possibly suffer drought, especially in areas that are currently drought-prone areas. These trends may be due to the unusually hot weather, the blow of the northeast monsoon (Singhrattna et. al., 2005) and the ridge of high pressure system from China. However, there is uncertainty in the expected drought because a drought is a complex event with many variables that should be considered such as the moisture in the air, wet and dryness of the ground, and the timing of the lack of rain.

In central and eastern Thailand, decreases in SDII, Rnn, Rx5day, CWD, and slight decreases of CDD indicate less intense and heavy frequent rainfall with shorter consecutive wet days during the wet season, which suggest that in the future these areas will become drier during the wet season. In the dry season, increases in SDII , Rx5day and Rnn along with decreases of both CDD and CWD suggest that rainfall may become more intense; heavy rainy days will be more frequent but not continual, which is why CDD is decreased.

In southern Thailand, extreme rainfall changes are both increasing and decreasing. The magnitude of change varies spatially and seasonally. On an annual basis, an increase of SDII indicates more intense rainfall in most areas. The wet spell will be decreased in the Southern Andaman Sea and increased in the southeastern part of southern Thailand. The dry spell will be shorter in the whole Southern region during all seasons.

\section{Conclusions}

To investigate the impact of global warming on future climate changes in regards to intensity, frequency, and duration of extreme precipitation over Thailand for the future period (2020-2029) relative to the 1990-1999 reference period under the IPCC A1B emission scenarios, MM5-RCM-forced CCSM3 outputs were used in the calculations of the following extreme rainfall indices (after biascorrection was applied): SDII (simple daily precipitation intensity index), Rnn (the number of heavy rainfall days), Rx5day (the monthly maximum consecutive 5-day rainfall amount), CDD (the annual maximum of consecutive dry days), CWD (the annual maximum of consecutive wet days). The average and cycle of annual rainfall in the reference period are reproduced reasonably by Post-MM5-RCM. From the projection of extreme indices changes, the conclusions are presented below:

1. Most areas of northern, western, and northeastern Thailand will likely become wetter in the wet season and drier in dry season. The risk of flood is probably amplified in the lower-northern and western regions while the risk of drought is more possibly in northeastern and upper-northern Thailand.

2. Central and eastern Thailand will become drier during the wet season while in the dry season rainfall will become more intense, and rainy days will become more scattered with a higher number of heavy rainy days.

3. Southern Thailand will have more intense rainfall on an annual basis. The length of the wet spell will decreased in the Southern Andaman Sea and increased in the East-Southern Region. The dry spell will be shorter throughout this region for all seasons.

\section{Acknowledgment}

This work is funded by the National Research Council of Thailand (NRCT). The MM5-RCM outputs were provided by the Atmospheric Physics Research Unit, Faculty of Science, Chiang Mai University on The Thailand Research Fund (TRF) research project. The daily observational data were provided by Thai Meteorological Department (TMD).

References

Chidthaisong A. (2010), Thailand Climate Change Information, Thailand Research Fund's Research Development and Coordination Center for Global Warming and Climate Change; TGLOB, The Thailand Research Fund, 92pp. 
Chotamonsak C., Salathé E.P., Kreasuwan J., Chantara S. and Siriwitayakorn K. (2011), Projected climate change over Southeast Asia simulated using a WRF regional climate model, Atmospheric Science Letters, 12(2), 213219.

Fowler A.M. and Hennessy K.J. (1995), Potential impacts of global warming on the frequency and magnitude of heavy precipitation, Natural Hazards, 11(3), 283-303.

Groisman P.Y., Karl T.R., Easterling D.R., Knight R.W., Jamason P.F., Hennessy K.J., Suppiah R., Page C.M., Wibig J., Fortuniak K., Razuvaev V.N., Douglas A., Forland E., and Zhai P.M. (1999), Changes in the probability of heavy precipitation: Important indicators of climate change, Climatic Change, 42, 243-283.

Houghton J.T., Ding Y., Griggs D.J. and Noguer M. (2001), Climate Change 2001: The Scientific Basis. Contribution of Working Group I to the Third Assessment Report of the Intergovernmental Panel on Climate Change. Cambridge, United Kingdom, New York, USA, Cambridge University Press, 881 pp.

Karl T.R., Knight R.W. and Plummer N. (1995), Trends in high-frequency climate variability in the twentieth century, Nature, 377, 217-220.

Kothavala Z. (1997), Extreme precipitation events and the applicability of global climate models to the study of floods and droughts, Mathematics and computers in simulation, 43(3), 261-268.

Lehner B., Döll P., Alcamo J., Henrichs T. and Kaspar F. (2006), Estimating the impact of global change on flood and drought risks in Europe: a continental, integrated analysis, Climatic Change, 75(3), 273-299.

Lenderink G., Buishand A. and Deursen W.V. (2007), Estimates of future discharges of the river Rhine using two scenario methodologies: direct versus delta approach, Hydrology and Earth System Sciences, 11(3), 11451159.

Limjirakan S. and Limsakul A. (2012), Observed Trends in Surface Air Temperatures and Their Extremes in Thailand from 1970 to 2009, Journal of the Meteorological Society of Japan, 90(5), 647-662.

Limsakul A., Limjirakan S. and Sriburi T. (2010), Observed Changes in daily rainfall extreme along Thailand's coastal zones, Journal of Environmental Research, 32(1), 49-68.

Manabe S., Wetherald R.T. and Stouffer R.J. (1981), Summer dryness due to an increase of atmospheric $\mathrm{CO}_{2}$ concentration, Climatic Change, 3(4), 347-386.

MccarthyJ. J. (Ed) (2001), Climate change 2001: impacts, adaptation, and vulnerability: contribution of Working Group II to the third assessment report of the Intergovernmental Panel on Climate Change. Cambridge University Press, $1032 \mathrm{pp}$.

Mizuta R., Uchiyama T., Kamiguchi K., Kitoh A. and Noda A. (2005), Changes in extremes indices over Japan due to global warming projected by a global 20-km-mesh atmospheric model, Sola, 1(0), 153-156.

Nastos P.T., Kapsomenakis J. Douvis K.C. (2013), Analysis of precipitation extremes based on satellite and highresolution gridded data set over Mediterranean basin, Atmospheric Research, 131, 46-59

Oikonomou C., Flocas H.A., Hatzaki M., Asimakopoulos D.N. and Giannakopoulos C. (2008), Future changes in the occurrence of extreme precipitation events in eastern Mediterranean, Global NEST Journal, 10, 255-262.

Singhrattna N., Rajagopalan B., Kumar K.K. and Clark M. (2005), Interannual and interdecadal variability of Thailand summer monsoon season, Journal of Climate, 18(11), 1697-1708.

Solomon S. (Ed.) (2007), Climate change 2007-the physical science basis: Working group I contribution to the fourth assessment report of the IPCC (Vol. 4), Cambridge University Press, 996 pp.

Stowasser M., Wang Y. and Hamilton K. (2007), Tropical cyclone changes in the Western North Pacific in a global warming scenario, Journal of Climate, 20(11), 2378-2396.

Suwanmanee Y. (2012), Trends of extremes indices in daily air temperature and rainfall over Thailand, Climatological Center, Thailand Meteorological Department, Technical Document No.551.524-01-2012.

Wetterhall F., Pappenberger F., He Y., Freer J. and Cloke H.L. (2012), Conditioning model output statistics of Regional Climate Model precipitation on circulation patterns, Nonlinear Processes in Geophysics, 19, 623-633.

Zhai P., Sun A., Ren F., Liu X., Gao B. and Zhang Q. (1999), Changes of climate extremes in China, Climatic Change, 42, 203-218. 